\title{
Study of Specific Dermatoses of Pregnancy and Skin Diseases affected by Pregnancy in a Tertiary Care Rural Hospital
}

\author{
${ }^{1}$ Stuti Khare, ${ }^{2}$ Adarshlata Singh
}

\section{ABSTRACT}

Aims and objectives: To study the various specific dermatoses of pregnancy and changes due to pregnancy.

Study design: A cross-sectional study was conducted in a tertiary care center, Department of Dermatology and Department of Obstetrics and Gynecology.

Materials and methods: A total of 400 pregnant females were enrolled and studied for various cutaneous changes of pregnancy. In pregnant females with specific dermatoses of pregnancy, detailed clinical examination was done regarding the morphology, pattern, and distribution of lesions. Routine blood investigations were done in all pregnant females. Biopsy was done wherever required.

Results: Among 400 pregnant females, we found 38 (9.5\%) to be having specific dermatosis of pregnancy. The most common specific dermatosis of pregnancy was prurigo of pregnancy $(4.75 \%)$, followed by pruritic urticarial papules and plaques (PUPP) of pregnancy (4\%), intrahepatic cholestasis (ICP) of pregnancy $(0.25 \%)$, and pruritic folliculitis of pregnancy $(0.125 \%)$. In $9.5 \%$ females, skin diseases were caused due to pregnancy.

Keywords: Pregnancy, Skin changes, Specific dermatoses.

How to cite this article: Khare S, Singh A. Study of Specific Dermatoses of Pregnancy and Skin Diseases affected by Pregnancy in a Tertiary Care Rural Hospital. Int J Recent Surg Med Sci 2017;3(2):75-78.

Source of support: Nil

Conflict of interest: None

\section{INTRODUCTION}

Pregnancy is the most crucial period in a woman's life and is a period of profound immunological, endocrinological, metabolic, and vascular changes which are tolerated by the body for a relatively short time. ${ }^{1}$ Although

\footnotetext{
${ }^{1}$ Resident, ${ }^{2}$ Professor and Head

${ }^{1}$ Department of Dermatology, Datta Meghe Institute of Medical Sciences, Wardha, Maharashtra, India

${ }^{2}$ Department of Dermatology, Acharya Vinoba Bhave Rural Hospital, Wardha, Maharashtra, India

Corresponding Author: Stuti Khare, Resident, Department of Dermatology, Datta Meghe Institute of Medical Sciences Wardha, Maharashtra, India, Phone: +918308104228, e-mail: akshat.shukla006@gmail.com
}

physiological changes that occur with pregnancy are extensive, they are also temporary; when pregnancy ends, the woman's body returns virtually to its prepregnant state. Pregnancy can also alter the course of certain infections like candidiasis, herpes, and other viral infections; immunological diseases like psoriasis vulgaris, pemphigus vulgaris, lichen planus, systemic lupus erythematosus (SLE), systemic sclerosis; metabolic diseases like porphyria cutanea tarda; connective tissue disorders like Ehlers-Danlos syndrome, pseudoxanthoma elasticum, etc. ${ }^{2}$ However, there are few inflammatory skin dermatoses that are specific to pregnancy and are seen only in pregnancy. Though most of them are benign and resolve, few can risk fetal life and require antenatal surveillance. It is thus essential to recognize and differentiate the physiological skin changes from specific dermatosis of pregnancy in order to abstain from unnecessary medical intervention which can be harmful. ${ }^{3}$

\section{MATERIALS AND METHODS}

This cross-sectional observational study was carried out in the Department of Dermatology and Department of Obstetrics and Gynecology of a tertiary care rural hospital, and 400 pregnant females were enrolled. A written informed consent was taken and a detailed history, including demographic data, past obstetric history, parity, chief dermatological complaints, onset in relation to the duration of pregnancy, presence of itching, history of atopy, medications, similar complaints in previous pregnancies, family history, exacerbating factors, associated medical or skin disorders, was elicited. General physical, systemic, and complete cutaneous examination was carried out in all patients; morphology and distribution of lesions was recorded. The presence of any coincident dermatoses developing during pregnancy was studied. Routine investigations were done.

\section{RESULTS}

Specific dermatosis of pregnancy was seen in $9.5 \%$. The most common specific dermatosis of pregnancy was prurigo of pregnancy $(4.75 \%)$, followed by PUPP of pregnancy accounting for $4 \%$, followed by polymorphic 


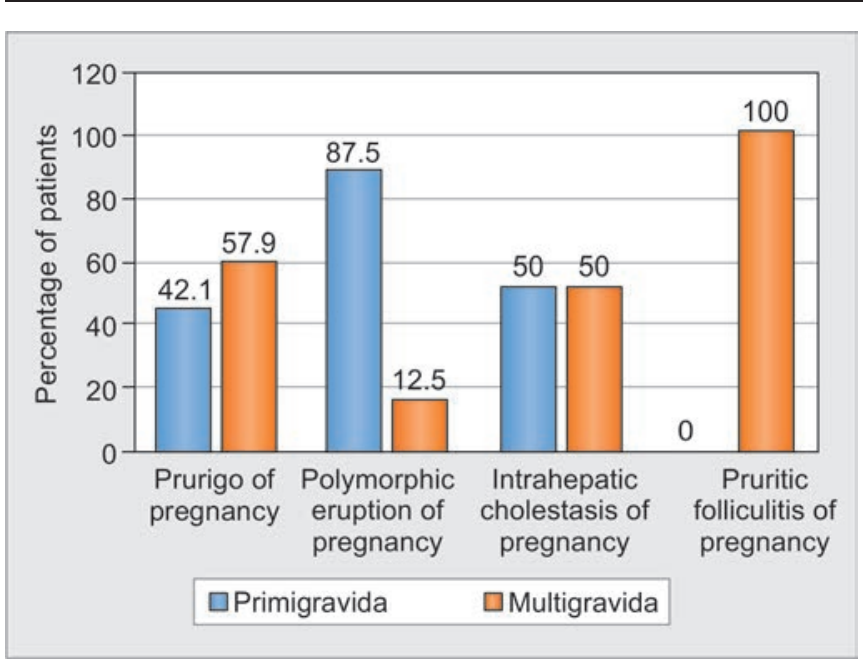

Graph 1: Distribution of pregnant females with specific dermatoses with respect to gravida

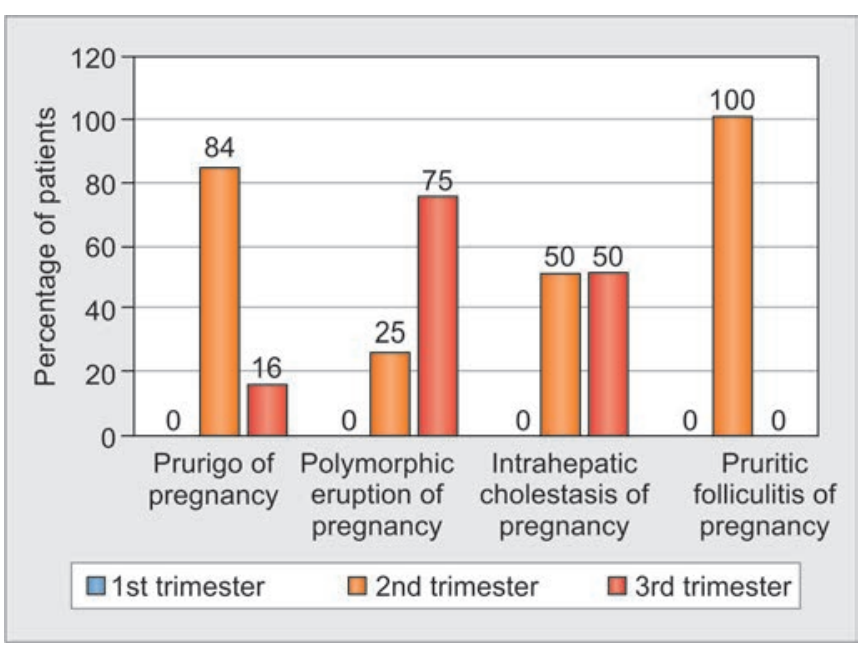

Graph 2: Distribution of pregnant females having onset of specific dermatoses of pregnancy with respect to trimester of pregnancy

Table 1: Distribution of pregnant females with various skin diseases affected by pregnancy

\begin{tabular}{|c|c|c|c|c|c|c|}
\hline \multirow[b]{2}{*}{ Disease } & \multirow[b]{2}{*}{ Number of patients } & \multicolumn{5}{|c|}{ Course } \\
\hline & & Exacerbated & Regression & Remission & New onset & No change \\
\hline Photomorphic light eruption & 4 & 4 & - & - & - & - \\
\hline Acne vulgaris & 16 & 8 & - & 4 & 4 & - \\
\hline Eczema & 4 & 4 & - & - & - & - \\
\hline Psoriasis & 2 & & 2 & - & - & - \\
\hline Contact dermatitis & 3 & 3 & - & - & - & - \\
\hline Lichen planus & 2 & 2 & - & - & - & - \\
\hline Vitiligo & 1 & 1 & - & - & - & - \\
\hline Neurofibromatosis & 1 & 1 & - & - & - & - \\
\hline Darier disease & 1 & - & - & - & - & 1 \\
\hline Atopic dermatitis & 2 & 2 & - & - & - & - \\
\hline Hypertrophic scar & 1 & & & & & \\
\hline Keloid & 1 & & & & & \\
\hline Total & 38 & & & & & \\
\hline
\end{tabular}

Table 2: Incidences of specific dermatosis of pregnancy in various Indian studies

\begin{tabular}{lllll}
\hline $\begin{array}{l}\text { Specific } \\
\text { dermatosis }\end{array}$ & $\begin{array}{l}\text { Chaudhary } \\
\text { et } \mathrm{al}^{9} \text { (\%) }\end{array}$ & $\begin{array}{l}\text { Shivakumar } \\
\text { et }\left.\right|^{10} \text { (\%) }\end{array}$ & $\begin{array}{l}\text { Kumari } \\
\text { et } \mathrm{a}^{3} \text { (\%) }\end{array}$ & $\begin{array}{l}\text { Present } \\
\text { study (\%) }\end{array}$ \\
\hline $\begin{array}{l}\text { Prurigo of } \\
\text { pregnancy }\end{array}$ & 1.2 & 9.41 & 10.16 & 4.75 \\
$\begin{array}{l}\text { Pruritic folliculitis } \\
\text { Polymorphic }\end{array}$ & 0.2 & - & 0.16 & 0.25 \\
$\begin{array}{l}\text { eruption of } \\
\text { pregnancy }\end{array}$ & & 2.35 & 2.3 & 4 \\
$\begin{array}{l}\text { Intrahepatic } \\
\text { cholestasis of } \\
\text { pregnancy }\end{array}$ & 0.1 & - & - & 0.5 \\
\hline
\end{tabular}

eruption of pregnancy in 16 cases (4\%), ICP of pregnancy in 2 cases $(0.25 \%)$, and pruritic folliculitis of pregnancy in 1 case $(0.125 \%)$ (Figs 1 to 4 , Graphs 1 and 2, Tables 1 and 2 ).

\section{DISCUSSION}

There are basically three crucial changes that occur during pregnancy: endocrinological, immunological, and metabolic. During pregnancy, the maternal immune response is extensively altered to allow the fetus to attach to the mother. Cytokine profile is altered, leading to a tendency toward the Th2 cytokines (IL-4, IL-5, IL-10, IL-13), which favors the maintenance of fetal survival. Hormonal changes during pregnancy also lead to an overall preference of the Th2 cytokine profile. ${ }^{4}$

\section{Specific Dermatosis of Pregnancy}

Regarding the specific dermatosis of pregnancy, the most common classification in literature proposed by AmbrosRudolph et $\mathrm{al}^{5}$ was applied in this study. In a study done by Hassan et al, ${ }^{6}$ Sharath Kumar et al, ${ }^{7}$ and Chander et $\mathrm{al}^{8}$ it was reported to be $4.9,18$, and $5 \%$ respectively.

The pathogenesis of atopic eruption of pregnancy (AEP) is thought to be triggered by pregnancy-specific immunological changes that are reduced cellular immunity and production of Th1 cytokines [interleukin (IL)-2, interferon-gamma, IL-12], which stands in contrast 

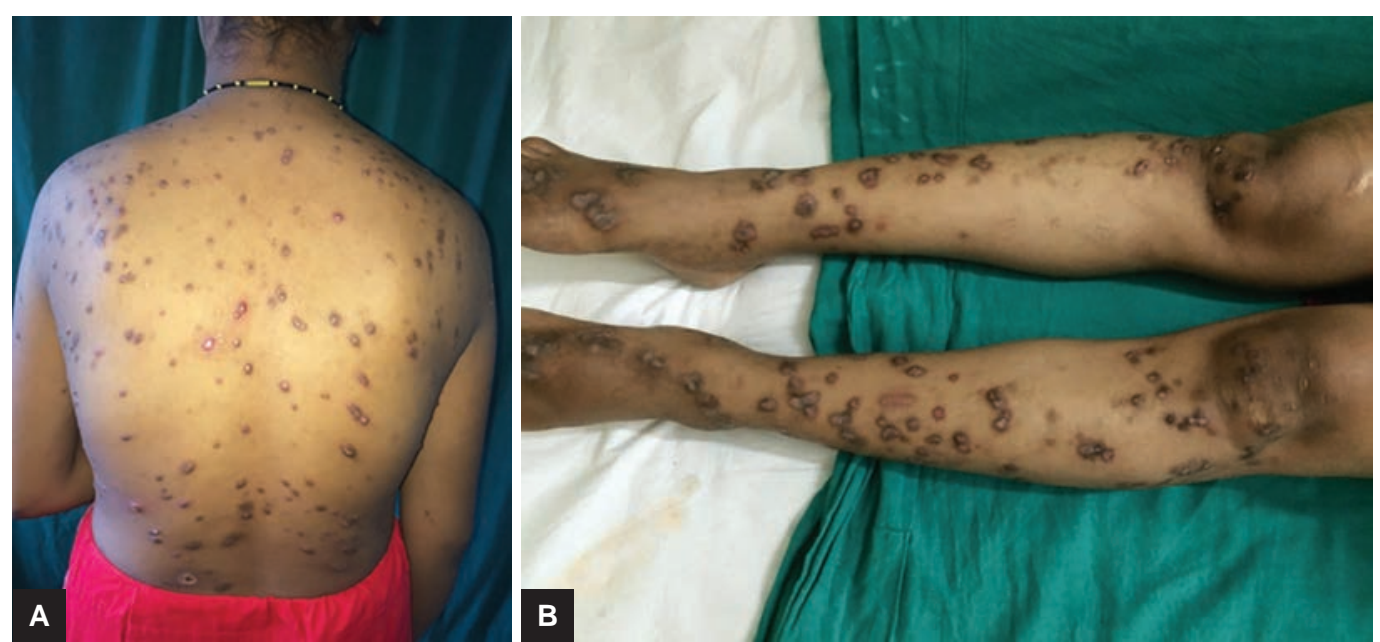

Figs 1A and B: A 28-year-old multigravida showing prurigo of pregnancy

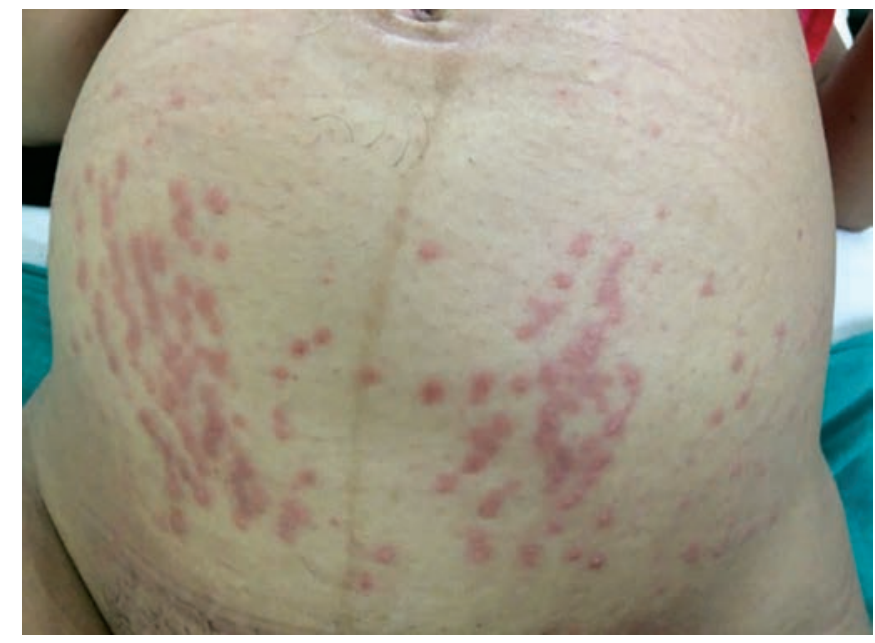

Fig. 2: 22-year-old primigravida with PUPP characteristic periumbilical sparing seen

to the dominant humoral immunity and increased secretion of Th2 cytokines (IL-4, IL-10). The PUPP is often associated with excessive maternal weight gain and multiple pregnancies. The pathogenesis of PUPP remains unclear. The main theories proposed are abdominal distension, hormonal and immunological factors. The fact that PUPP starts within striae distensae at the time of greatest abdominal distension favors connective tissue damage due to overstretching and triggering inflammatory process. In the present study, there were two females with ICP. Both presented with sudden onset of severe pruritus that started on one part but soon became generalized. There were no primary lesions and just excoriations were seen due to continuous itching by the patients. For both these patients, we got all routine investigations including liver function and ultrasonography abdomen done, which turned out to be normal in both these patients. Serum bile acid levels could not be measured due to the unavailability of this test at our center.

\section{Skin Diseases caused due to Pregnancy}

Out of 400 pregnant females, $9.5 \%$ females had skin diseases that were due to by pregnancy. Study conducted by
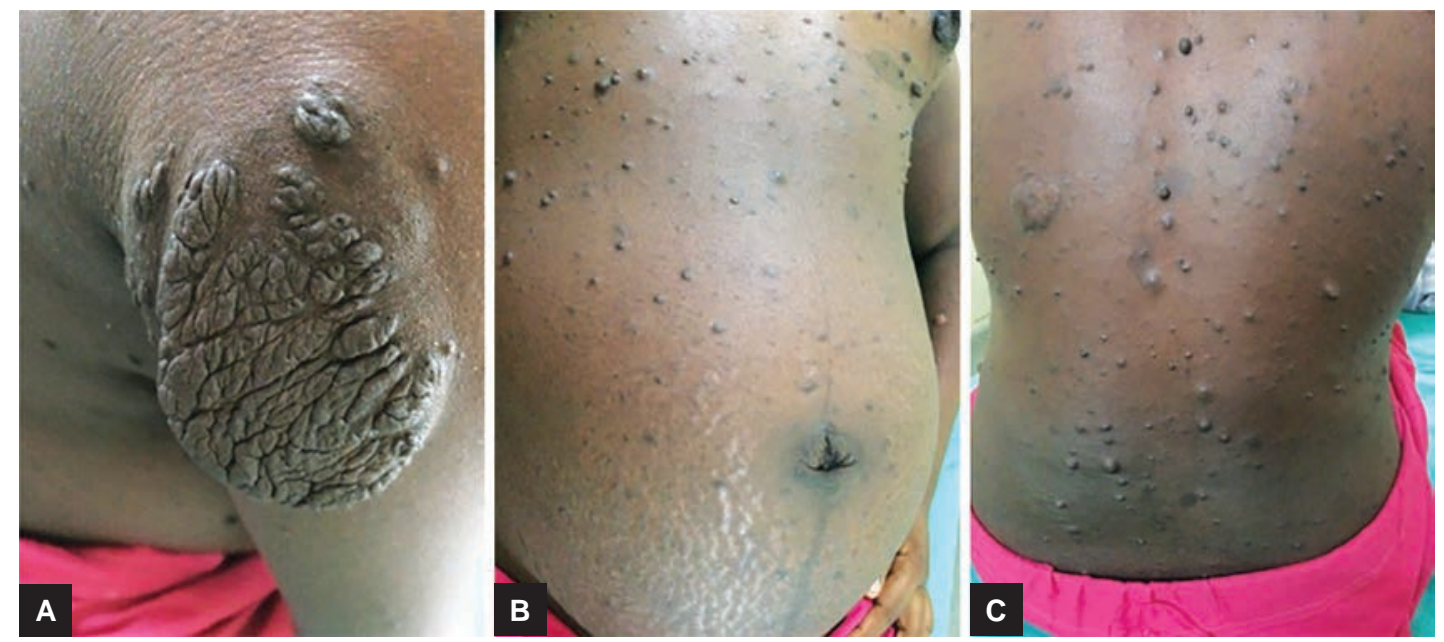

Figs 3A to C: Darier's disease regressed in a 30-week primigravida 


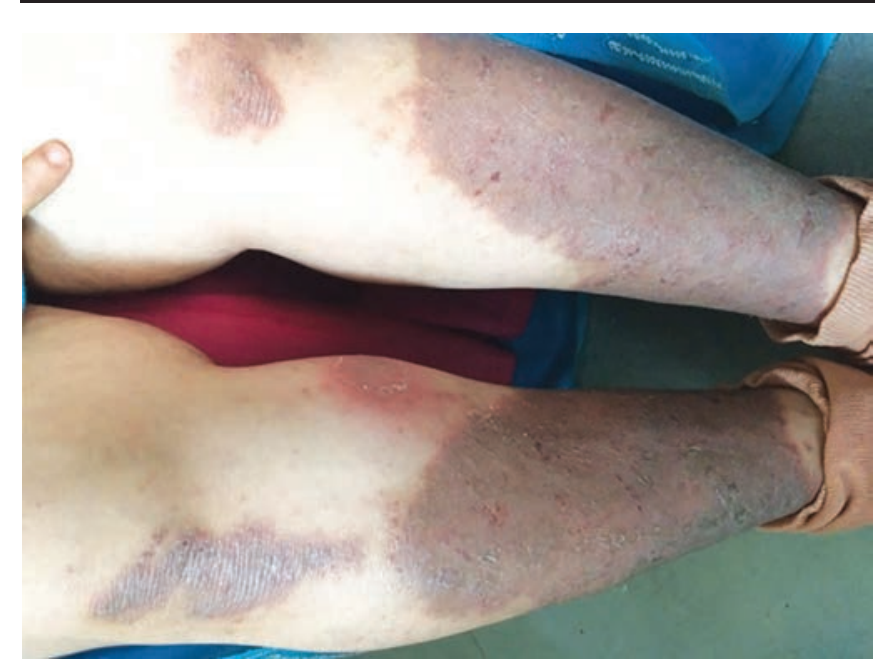

Fig. 4: Psoriasis vulgaris in a 3rd trimester female which showed regression during pregnancy

Kumari et $\mathrm{al}^{3}$ reported that there were exacerbations in $0.83 \%$ cases of eczema, $1.9 \%$ cases of psoriasis, $1.1 \%$ cases in protein-losing enteropathy exacerbation of SLE, ichthyosis vulgaris in $0.16 \%$ cases, and neurofibromatosis in $0.4 \%$ cases. There was new onset of pemphigus and vitiligo in $0.16 \%$ cases. Diseases in which humoral immunity has a major role to play like atopic dermatitis are exacerbated, while diseases where cell-mediated immunity plays a role like psoriasis vulgaris, etc. might show regression.

\section{CONCLUSION}

From the above study, we concluded that AEP is the commonest specific dermatoses of pregnancy, which mostly occurs in the second trimester of pregnancy in multigravida. Intrahepatic cholestasis of pregnancy, a rare dermatosis, presents with only excoriations and without any primary lesions. Pregnancy also alters the course of diseases causing exacerbation in diseases like atopic dermatitis, vitiligo, and remission of diseases like psoriasis vulgaris.

\section{RECOMMENDATIONS}

It is important for the obstetrician and gynecologist to refer patients with skin complaints to the dermatologist because sometimes visualizing the skin does not rule out the possibility of specific dermatosis of pregnancy as in case of ICP where there are no active skin lesions.

\section{ACKNOWLEDGMENT}

The authors thank the faculty and residents of the Department of Dermatology, Obstetrics and Gynaecology for their valuable inputs, and patients for their kind cooperation.

\section{REFERENCES}

1. Pãunescu MM, Feier V, Pãuneseu M, Dorneanu F, SisakA, Ambros-Rudolph CM. Dermatoses of pregnancy. Acta Dermatoven APA 2008 Mar;17(1):4-10.

2. Mahboobe KA, Fatame A, Nahid S, Leila S, Mohammad AJ. Physiologic skin changes in pregnancy among patients of the postpartum ward in Shabih-Khani Hospital, Kashan. Res J Med Sci 2011;5(5):305-309.

3. Kumari R, Jaisankar TJ, Thappa DM. A clinical study of skin changes in pregnancy. Indian J Dermatol Venereol Leprol 2007 Mar-Apr;73(2):141.

4. Kar S, Krishnan A, Shivkumar PV. Pregnancy and skin. J Obstet Gynecol India 2012 Jun;62(3):268-275.

5. Ambros-Rudolph CM, Müllegger RR, Vaughan-Jones SA, Kerl H, Black MM. The specific dermatoses of pregnancy revisited and reclassified: results of a retrospective twocenter study on 505 pregnant patients. J Am Acad Dermatol 2006 Mar;54(3):395-404.

6. Hassan I, Bashir S, Taing S. A clinical study of the skin changes in pregnancy in Kashmir valley of North India: a hospital based study. Indian J Dermatol 2015 Jan-Feb;60(1): 28-32.

7. Sharath Kumar BC, Aneesh S, Gopal MG, Ramesh M, Nandini, Gupta D. Clinical and epidemiological study of cutaneous manifestations of pregnancy. J Evol Med Dent Sci 2013 Nov;2(44):8667-8677.

8. Chander R, Garg T, Kakkar S, Jain A. Specific pregnancy dermatoses in 1430 females from Northern India. J Dermatol Case Rep 2011 Dec;5(4):69-73.

9. Chaudhary R, Mahakal N, Chauhan A, Modi K. Study of dermatological disorders in pregnancy. Int J Sci Study 2015 Nov;3(8):118-122.

10. Shivakumar V, Madhavamurthy P. Skin in pregnancy. Indian J Dermatol Venereol Leprol 1999 Jan-Feb;65(1):23-25. 